\title{
IMPACTOS DA UTILIZAÇÃO DE SISTEMA DE INFORMAÇÃO LOGÍSTICO NO COMPARTILHAMENTO DE INFORMAÇÕES NA CADEIA DE SUPRIMENTO DE SOBRESSALENTES DA MARINHA DO BRASIL
}

\author{
Rogério Ferraz Queiroz Miranda \\ Marinha do Brasil (MB) / Pontífice Universidade Católica do Rio de Janeiro (PUC-Rio) \\ rogeriomiranda87@gmail.com \\ Marcelo Reis Bezerra \\ Marinha do Brasil (MB) / Pontífice Universidade Católica do Rio de Janeiro (PUC-Rio) \\ marceloreisbezerra@gmail.com \\ Thadeu Costa Gigante \\ Marinha do Brasil (MB) / Pontífice Universidade Católica do Rio de Janeiro (PUC-Rio) \\ thadeu_gigante@yahoo.com.br \\ Diego Lopes Duarte \\ Marinha do Brasil (MB) / Universidade Federal Fluminense (UFF) \\ dlduarte@id.uff.br
}

\begin{abstract}
Resumo
A busca de melhorias na previsão de demanda e redução do efeito chicote com o uso do compartilhamento de informações é um assunto recorrente nos estudos atuais desenvolvidos por diversas empresas. Neste sentido, a Marinha do Brasil, para dar suporte às atividades voltadas à previsão e provisão dos recursos materiais necessários aos seus meios navais, incluíndo as Funções Logísticas Suprimento e Manutenção, dispõe do Sistema de Informação Logístico (SIL) conhecido como Sistema de Controle de itens de Sobressalente de Bordo (SISBORDO), o qual possui um enfoque operativo. No presente artigo, buscou-se investigar os impactos positivos advindos do compartilhamento de informações entre o Sistema de Abastecimento da Marinha (SAbM) e o consumidor final (Navios) na gestão integrada da Cadeia de Suprimento de Sobressalentes militar-naval por meio do SISBORDO. Para atingir o objetivo proposto, o estudo desenvolveu-se sob uma metodologia de pesquisa qualitativa e quantitativa, explicativa e bibliográfica, por meio de um estudo de campo. Os resultados alcançados são o incremento de aproximadamente $22 \%$ do nível de serviço, além da redução do capital imobilizado em estoques nos Centros de Distribuição e nos Navios. Nesse sentido, o artigo contribui para o incremento da disponibilidade e da eficiência logística dos Navios que operam em patrulhas navais nas bacias petrolíferas da Amazônia Azul, propiciando permanência e defesa nas áreas de exploração das riquezas do Pré-sal.

Palavras-Chaves: Marinha do Brasil; Sistema de Abastecimento da Marinha; SISBORDO; Compartilhamento de Informações; Efeito chicote; Previsão de demanda.
\end{abstract}

\footnotetext{
Abstract

The improvements searches in demand forecasting and reducing of "bullwhip effect" with the use of information sharing is a recurrent subject in the recent studies developed by several companies. Therefore, the Brazilian Navy, supporting the activities related to forecasting and provision of the necessary material resources for its ships, including the Logistic Functions Supply and Maintenance, uses the Logistics Information System (LIS) known as Spare Parts Control System (SISBORDO), which has an operative approach. In this article, its sought to investigate the positive impacts arising from the sharing of information between the Navy's Supply Chain Management System (SABM) and the final consumer
} 
(Ships) in the integrated management of the naval Spare Parts Supply Chain through the SISBORDO. To achieve the proposed objective, the study was developed under a qualitative and quantitative, explanatory and bibliographic research methodology, through a field study. The achieved results are the increase of approximately $22 \%$ of the level of service, besides the reduction of fixed capital in the stock in the distribution centers and ships. Thus, the article contributes to improve the availability and logistical efficiency of ships that operate in naval patrols at Amazonia Azul oil basins, providing permanence and protection in Pre-salt wealth exploitation areas.

Keywords: $\quad$ Brazilian Navy; Navy's Supply Chain Management System; SISBORDO; Information Sharing; Bullwhip effect; Demand forecasting.

\section{INTRODUÇÃO}

Com a ampliação da atuação política brasileira no cenário internacional, a Marinha do Brasil (MB) também tem expandido suas áreas de interesse operativo, em que diversos dos seus Navios participam de operações nacionais e internacionais. Para atender operações navais posicionadas no território nacional, tais como patrulhas navais nas bacias petrolíferas da Amazônia Azul, a MB desenvolve um esforço logístico que demanda, a todo momento, o conhecimento e compartilhanto das informações. Isso também ocorre nas operações em áreas de interesse internacional, como por exemplo, as operações de paz da ONU, a saber: MINUSTAH (Haiti); MINURSO (Saara Ocidental); UNMIL (Libéria); UNMIT (Timor Leste); UNOCI (Costa do Marfim); UNIFIL (Líbano). Algumas das operações supracitadas, além das necessidades de uma tropa terrestre, demandam, pelo menos, dois Meios Navais (um Navio titular e um Navio reserva) preparados e em condições de eficiência para a consecução da missão.

Ressalta-se que a preparação de um Navio envolve a prontificação de seus diversos sistemas, os quais constituem sistemas de máquinas para propulsão, sistema de geração de energia, sistema de comunicação, sistemas de armas, entre outros. Logo, a prontificação operativa de um Navio resulta da condição de operação de seus sistemas, que depende do fornecimento dos diversos componentes eletrônicos e não eletrônicos, de aviação, sobressalentes de máquinas e motores, bem como a realização de manutenções programadas e corretivas. Isso demonstra o imperativo por uma gestão eficiente e eficaz da Cadeia de Suprimentos de Sobressalentes pelo Sistema de Abastecimento da Marinha (SAbM), seja no controle de estoque nos Centros de Distribuição (CD), ou no compartilhamento de informações em um momento seguinte.

A estrutura organizacional da MB contempla um sistema constituído por Órgãos, processos e recursos interligados e interdependentes, elaborado com a finalidade de promover, manter e controlar o provimento do material necessário à manutenção das Forças e demais Órgãos Navais em condição de plena eficiência. Assim está definido o SAbM [31].

As atividades desenvolvidas no âmbito do SAbM vão desde determinações técnicas e correntes de necessidades a partir do estabelecimento de políticas de estoque para as distintas classes de materiais fornecidas pelo SAbM, passando pela obtenção no comércio nacional ou em fontes de obtenção internacionais até a entrega dos itens às Organizações Militares Clientes (Navios).

A gestão da Cadeia de Suprimentos de Sobressalentes no âmbito militar-naval é dificultada pelos altos custos envolvidos ao longo de toda Cadeia, pela demanda altamente errática e intermitente, pelo baixo nível de serviço praticado que gera falta de confiança no sistema, pela desatualização do banco de dados de itens de sobressalente, pela idade e ciclo de vida dos Navios, pelo relevante custo de falta (custo operativo imensurável), pelo risco/custo de obsolescência devido às características dos sistemas militares em constante transformação, pelo fato de a maioria das fontes de obtenção para itens militares estarem situadas no exterior, pelas restrições impostas na Lei de Licitações [6], pela ausência do compartilhamento de 
informações dos controles de estoques a bordo e pela deficiente integração entre as Funções Logísticas Manutenção e Suprimento [14; 18; 28], que trazem como principais consequências um grande número de respostas de falta de estoque aos pedidos dos Navios e elevado tempo de atendimento para correção destas faltas.

Visando reduzir as deficiências citadas, examinar-se-á o sistema de informação logístico chamado de SISBORDO, cuja correta operação permite o compartilhamento de informações entre os clientes e o SAbM, tais como a demanda histórica, o controle de estoques do Navio, o grau de essencialidade do material, a obtenção de itens fora do SAbM, entre outras.

Neste contexto, surge, de forma relevante, a questão: como o compartilhamento de informações pode contribuir para o desempenho de toda a Cadeia de Suprimentos de Sobressalentes da Marinha? Tal questionamento advém das diversas linhas de pesquisas recentes na literatura científica que também motivou este trabalho [1; 2; 7; 12].

Assim, o presente artigo busca investigar os impactos positivos advindos do compartilhamento de informações entre o SAbM e o consumidor final (Navios) na gestão integrada da Cadeia de Suprimentos de Sobressalentes militar-naval por meio do SISBORDO. A pesquisa proposta neste artigo é de suma importância dentro deste escopo, pois um conhecimento aprimorado da oferta e demanda aliado ao fluxo de informações ao longo da Cadeia é um dos componentes essenciais para maior integração e colaboração entre os pontos de origem (fornecedores, rastreados por CODEMP, ou Código de Empresa) e os clientes intermediários e finais [9].

\section{REVISÃO BIBLIOGRÁFICA}

As primeiras referências à logística surgiram em escritos relacionados às atividades militares, como na obra "Da Guerra” [8], embora, o uso efetivo do termo "logístico" tenha ocorrido, por sua vez, na obra “A Arte da Guerra” [20]. Porém, apenas Thorpe [32] efetuou a análise da logística como uma ciência [13]. Apesar dos estudos iniciais efetuados no âmbito militar, a sua evolução se deve ao setor empresarial, que em busca de maior vantagem competitiva, compôs aspectos técnico-científicos que colaboraram com o surgimento da Supply Chain ou Cadeia de Suprimento [3]. Define-se como Cadeia de Suprimento uma rede que interliga fornecedores (pontos de origem), fornecedores intermediários e consumidores finais, promovendo os fluxos de material e serviço, de informações e financeiro ao longo da Cadeia.

Consequência direta da globalização do mercado, o crescimento da competição no mercado empresarial impõe à Gestão da Cadeia de Suprimento ou Supply Chain Management (SCM), um importante viés de integração (informação e processos), de qualidade e de desempenho [17; 19; 26; 29; 30]. A Gestão da Cadeia de Suprimento possui consequências positivas no desempenho das empresas, incrementando em componentes essências os quais projetam as competências centrais da organização em um mercado competidor [17].

O avanço da integração do SCM necessitava de uma evolução no mesmo ritmo dos Sistemas de Informação (SI) que apoiavam os processos de negócios dentro da Cadeia de Suprimento. Tal avanço ocorreu com o surgimento do Enterprise Resource Planning (ERP), SI utilizado para dar maior integração dentro da Cadeia, a fim de gerar valor, diminuir custos, compartilhar informações, promovendo sinergia e aumentando a efetividade das Cadeias de Suprimentos [33].

O incremento de rendimento e competitividade na SCM por meio da implementação do sistema ERP é percebido em muitas empresas, sobretudo, na alavancagem da utilização do fluxo de informação em prol do aumento da flexibilidade e desempenho da organização [10].

Para Dinter [11], a utilização eficaz de informações logísticas é perseguida ao longo de toda a Cadeia em dois principais vetores, Adequate Information Supply e System Quality, que são alimentados por sete fatores críticos de sucesso: abrangência, flexibilidade, suporte, comunicação, parceria em negócios/Tecnologia da Informação e projeto colaborativo. A 
gestão de fluxo de informações para o compartilhamento nas camadas constituintes do SCM constitui-se em fator crítico de sucesso para o desempenho de toda Cadeia. Além disso, o nível de satisfação do consumidor final refletirá no nível de qualidade de toda a SCM [7;26].

Dentre os fatores que impactam o desempenho da SCM, há o nível de serviço, o custo de estoque e armazenagem, o custo de transporte, o custo de produção e o Efeito Chicote. O nível de serviço constitui-se da avaliação da Gestão da Cadeia de Suprimento sob os prismas da disponibilidade, do desempenho operacional (velocidade, consistência, flexibilidade e falhas) e da confiabilidade em função dos custos logísticos envolvidos [5]. O custo de estoque e armazenagem (capital, processamento dos pedidos, estocagem e manuseio), o custo de transportes (do fornecedor ao CD e do CD ao cliente) e custo de produção (omitido neste artigo por não compor a Cadeia de Suprimentos de Sobressalentes do órgão focal até o cliente) perfazem o custo logístico total a ser analisado na avaliação do nível de serviço.

Quanto ao Efeito Chicote ou bullwhip effect, pode ser definido como a variação quantitativa dos pedidos, amplificando a demanda real do consumidor final até ao ponto de origem/fornecedor, passando por toda Cadeia de Suprimento. O Efeito Chicote foi estudado primeiramente por Forrester [15], pelo qual também é conhecido como Efeito Forrester. Tal variação impõe consequências maléficas ao desempenho da Cadeia, tais como desperdício de recursos, excesso de estoques, aumento do custo logístico e diminuição da eficiência da Cadeia de Suprimentos.

As causas do Efeito Chicote são classificadas como causas operacionais e causas conjunturais para alguns autores, como Bhattacharya e Bandyopadhyay [4]. Na Figura 1, visualizam-se as causas delimitadas:

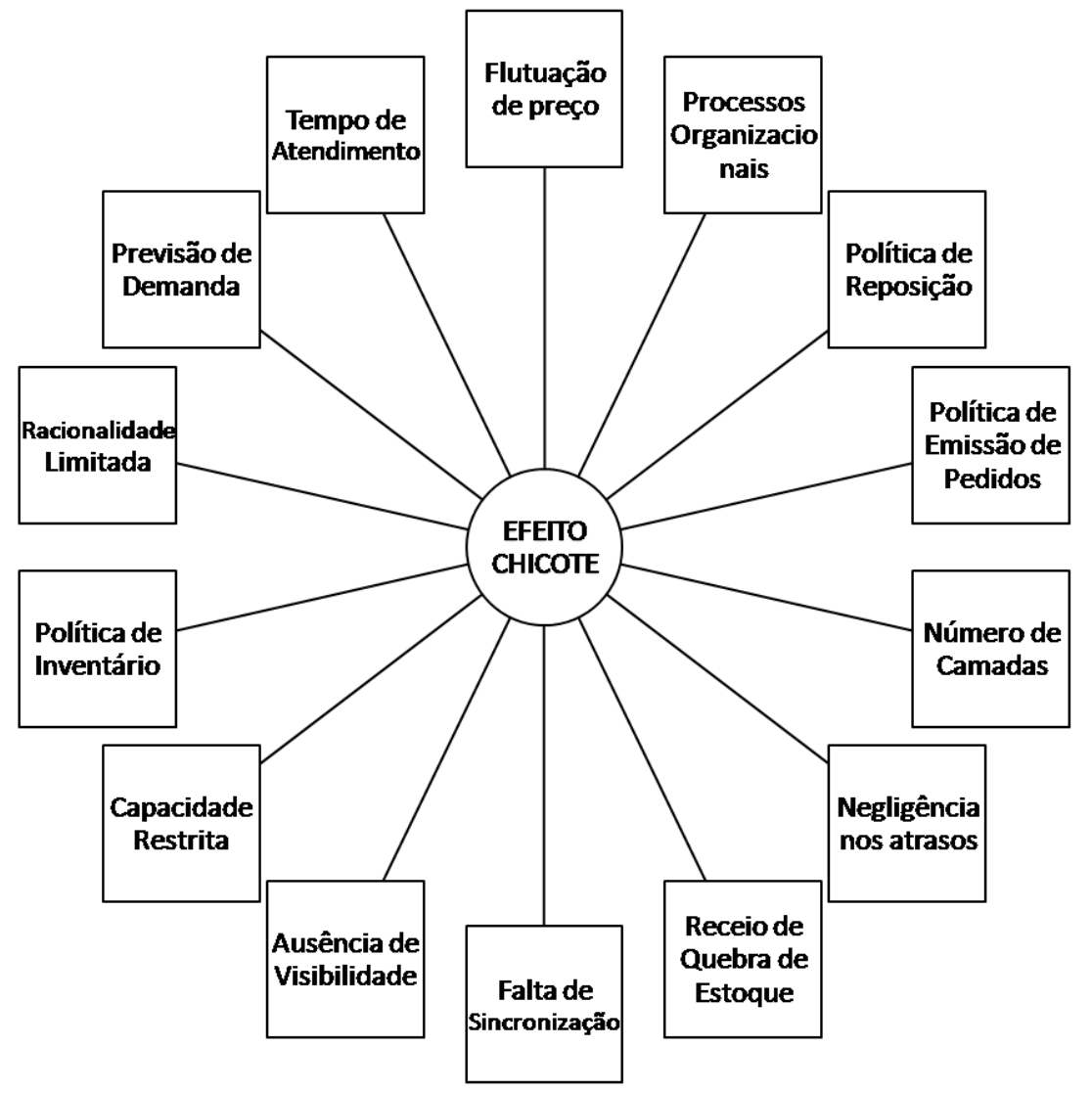

FIGURA 1. Causas do Efeito Chicote na Cadeia de Suprimento.

Fonte: Adaptado de Bhattacharya e Bandyopadhyay [4].

Apesar de não citarem a falta de compartilhamento de informação como uma das causas do Efeito Chicote, pesquisas recentes defendem que esta deficiência contribui para um desempenho negativo da Cadeia de Suprimento [24; 25; 34], em função da incerteza imposta na demanda do consumidor final. Não obstante, como já foi citado, a má coordenação entre 
membros da cadeia de abastecimento é apontada como catalisador da ausência de compartilhamento de informações [21].

Jaarsveld et al. [18] apresenta o $2 S$ ou two-step method, um método de previsão de demanda baseado não só nos itens de sobressalente demandados, mas também na quantidade histórica de operações de manutenção conduzidas por equipamento e na média de itens de sobressalente consumidos. Em termos de Doutrina Logística Militar, resultaria no maior compartilhamento de informações visando ao incremento da integração entre Funções Logísticas Manutenção e Suprimento. Além disso, o compartilhamento da informação aplicado ao método $2 S$ reduz em $20 \%$ o erro da previsão de demanda.

\section{METODOLOGIA DE PESQUISA}

\subsection{A Estratégia de Pesquisa: Classificações e Métodos Científicos}

Em se tratando de classificação da pesquisa, o estudo de Gil [16] tem sido utilizado em larga escala como parâmetro de definições em trabalhos científicos. Seus estudos servem de inspiração e são referência sobre os assuntos relacionados à pesquisa científica.

Sob o ponto de vista da sua natureza, Gil [16] define que as pesquisas podem ser básicas ou aplicadas. O presente estudo é definido sob um ponto de vista de uma pesquisa aplicada, pois gera conhecimentos que têm aplicabilidade na solução de problemas específicos.

Sob o ponto de vista da sua abordagem, Gil [16] define que as pesquisas podem ser classificadas como quantitativas e qualitativas. Este estudo possui as duas abordagens, pois, além de analisar de maneira numérica tendências, atitudes ou opiniões de uma população a partir de um estudo de uma amostra dela, são utilizados métodos qualitativos interativos e humanísticos, baseados na observação.

Sob o ponto de vista de seus objetivos, Gil [16] define que as pesquisas podem sem exploratórias, descritivas ou explicativas. Este estudo é definido com uma pesquisa explicativa, pois tem como objetivo central a identificação dos fatores que determinam ou contribuem para a ocorrência dos fenômenos.

Sob o ponto de vista dos procedimentos técnicos utilizados, Gil [16] atribui um grau de importância elevado a este fator, dadas as suas afirmações de que o procedimento adotado para a coleta de dados é o elemento mais importante da pesquisa. Assim, podem ser definidos dois grandes grupos de delineamentos: aqueles cujos dados são advindos das fontes de papel ou aqueles cujos dados são fornecidos por pessoas. Estão no primeiro grupo as pesquisas bibliográficas e as pesquisas documentais. O segundo grupo é constituído dos seguintes tipos de pesquisa: Experimental, Ex-Post Facto, Estudo de Coorte, Levantamento, Estudo de Campo, Estudo de Caso, Pesquisa-Ação e Pesquisa Participante. O presente trabalho classifica-se, num primeiro momento, como uma pesquisa bibliográfica, pois foi desenvolvida com base em material já elaborado, constituído principalmente de livros e artigos científicos, utilizando-se das contribuições de diversos autores sobre determinado assunto, e, num segundo momento, como um Estudo de Campo, pois segue à observação de fatos e fenômenos exatamente como ocorrem no real, à coleta de dados referentes aos mesmos e, finalmente, à análise e interpretação desses dados, com base numa fundamentação teórica consistente, visando compreender e explicar o problema pesquisado.

Em se tratando de método cientifico, pode-se definir este fenômeno como o conjunto de processos ou operações mentais que se deve empregar na investigação; esta é a linha de raciocínio adotada na pesquisa. É o agrupamento das atividades sistemáticas e racionais que, com maior segurança e economicidade, permite alcançar conhecimentos válidos e verdadeiros, indicando o caminho a ser seguido, detectando erros e auxiliando as decisões do autor [22]. Segundo Lakatos e Marconi [22], os métodos que fornecem as bases lógicas à investigação são: dedutivo, indutivo, hipotético-dedutivo, dialético e fenomenológico.

Sob o ponto de vista do método científico empregado, afirma-se que o presente estudo utilizou-se de todos os métodos apresentados. Em diversos momentos, utilizou-se de 
interpretações dinâmicas, apresentando hipóteses ou deduzindo fatos. Na verdade, não existe apenas uma maneira de raciocínio capaz de dar conta do complexo mundo das investigações científicas. Este autor, inclusive, considera que a utilização de métodos diferentes em uma pesquisa amplia as possibilidades de análise e de obtenção de respostas para o problema em estudo.

\subsection{Delineamento da Pesquisa}

Como delineamento da pesquisa, determinou-se uma classe específica de Navio que possui os sistemas mais sofisticados e de maior popularidade entre Navios da Esquadra Brasileira: as Fragatas Classe Niterói (FCN). Buscou-se inferir a quantidade dos principais itens de sobressalente pertencentes às FCN estocados nos Navios; segregaram-se os itens de sobressalente em famílias em função do departamento do Navio ou em função da aplicação em sistemas/equipamentos, conforme preconiza a classificação atribuída pelo símbolo de jurisdição que é dado a cada item de sobressalente e já consta do SISBORDO. Este artigo delimitar-se-á aos itens cujo símbolo de jurisdição é designado como “CH”, utilizados nas manutenções de $1^{\circ}$ Escalão (realizadas pela própria tripulação do Navio), conforme retrata a Tabela 1, com dados de pesquisa referentes à Fragata "Defensora" (segunda de uma série de seis FCN ordenadas na década de 70 e também é a segunda construída pela Vosper Thornycroft Ltd., em Woolston, Hampshire, Reino Unido), representando as Fragatas pertencentes à Classe Niterói no que se refere ao quantitativo de itens de sobressalente pertencentes à cadeia logística das FCN:

TABELA 1 - Itens de sobressalente por Símbolo de Jurisdição

\begin{tabular}{|c|c|c|c|}
\hline $\begin{array}{l}\text { Símbolo } \\
\text { de } \\
\text { Jurisdição }\end{array}$ & Discriminação do material & $\begin{array}{l}\text { Quantidade de } \\
\text { itens aplicados } \\
\text { e/ou dotados a } \\
\text { bordo }\end{array}$ & $\begin{array}{l}\text { Percentual } \\
\text { representativo } \\
\text { do SJ (\%) }\end{array}$ \\
\hline $\mathrm{CH}$ & $\begin{array}{l}\text { Componentes não eletrônicos dos seguintes sistemas: } \\
\text { estrutural, propulsão, geração e distribuição de energia } \\
\text { elétrica, vapor; ar comprimido, controle do Navio e de } \\
\text { avarias, etc. }\end{array}$ & 18.143 & 46,72 \\
\hline $\mathrm{X}$ & $\begin{array}{l}\text { Componentes não eletrônicos de equipamentos de } \\
\text { detecção e de comando e controle dos sistemas de armas. }\end{array}$ & 8.920 & 22,97 \\
\hline FN & $\begin{array}{l}\text { Componentes eletrônicos de equipamentos de detecção e } \\
\text { de comando e controle dos sistemas de armas. }\end{array}$ & 6.480 & 16,69 \\
\hline $\mathrm{CN}$ & $\begin{array}{l}\text { Componentes eletrônicos dos seguintes sistemas: } \\
\text { estrutural, propulsão, geração e distribuição de energia } \\
\text { elétrica, vapor; ar comprimido, controle do Navio e de } \\
\text { avarias, etc. }\end{array}$ & 2.265 & 5,83 \\
\hline NN & $\begin{array}{l}\text { Componentes eletrônicos de equipamentos de } \\
\text { comunicações e cripto em geral. }\end{array}$ & 1.375 & 3,54 \\
\hline AN & $\begin{array}{l}\text { Componentes discretos e itens de consumo de natureza } \\
\text { eletrônica, de aplicação característica em equipamentos } \\
\text { de lançamento dos sistemas de armas, etc. }\end{array}$ & 884 & 2,28 \\
\hline NH & Sobressalentes eletrônicos & 761 & 1,97 \\
\hline Total & Itens de sobressalente com maior significância a bordo & 38.828 & 100 \\
\hline
\end{tabular}

As fragatas se comportam como um varejista perante os departamentos existentes nos Navios. Os departamentos de Máquinas, de Armamento e de Operações são considerados consumidores finais, cada qual responsável pela manutenção de seus sistemas e equipamentos específicos [28]. Considera-se o SAbM como órgão focal da Cadeia de Suprimentos de Sobressalentes, como mostra a Figura 2: 


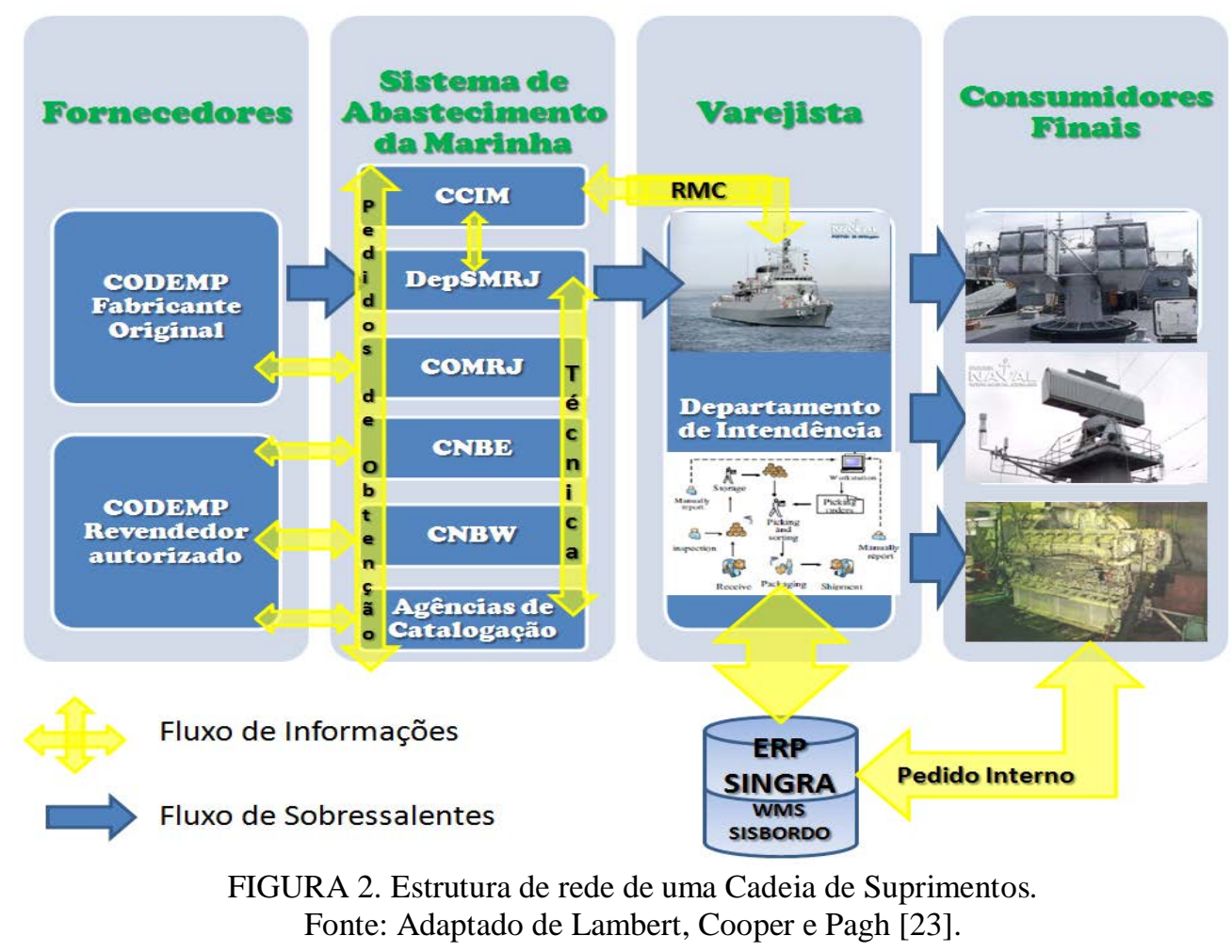

Efetuou-se a análise dos estoques dos Navios e o atendimento da demanda conhecida com base nos estoques excedentes nos próprios clientes; e como esse compartilhamento de informações (com e sem a utilização do SISBORDO) poderia reduzir níveis de estoques nos clientes e no Centro de Distribuição, bem como incrementar os níveis de serviços. Também analisou-se o Efeito Chicote [15] entre varejista (Navio) e Centro de Distribuição. Por fim, avaliou-se a importância da utilização de informações constantes do SISBORDO no aperfeiçoamento de métodos de previsão de demanda para a Cadeia de Suprimentos de Sobressalentes.

\section{O SISTEMA DE INFORMAÇÃO LOGÍSTICO E IMPACTOS DE SUA UTILIZAÇÃO: UM ESTUDO DE CAMPO}

Os pedidos de itens de sobressalente ínsitos na linha de fornecimento do SAbM são inseridos por meio de Requisição de Material para Consumo (RMC) no SISBORDO pelos Navios. Sendo as mesmas envidas, via Comando Imediatamente Superior, ao Centro de Controle de Inventário da Marinha, que irá aprovar, ou não, a RMC por meio do Sistema de Informações Gerenciais de Abastecimento (SINGRA), o sistema ERP da Marinha. Ato contínuo, diariamente os Centros de Distribuição cumprem suas programações de entregas aos Navios.

As decisões quanto aos níveis de estoque nos Centros de Distribuição, bem como a estratégia de reposição de estoque para os distintos itens, são realizadas pelos gerentes do Centro de Controle de Inventário, com relevante participação dos gerentes dos Órgãos de Obtenção, considerando-se variáveis de mercado, custos logísticos envolvidos e arcabouço jurídico. Ressalta-se aqui a importância de ferramentas apropriadas de apoio à tomada de decisão ao longo de toda a cadeia.

Por meio da Tabela 1, nota-se que os itens de sobressalente pertencentes ao Símbolo de Jurisdição "CH” possuem maior significância em termos qualitativo e quantitativo por representarem sobressalentes de sistemas vitais a bordo para a prontificação do Navio, bem como por representarem $46,72 \%$ de todos os sobressalentes utilizados a bordo.

Delimitada a família de sobressalentes cujo símbolo de jurisdição é “CH”, observouse dois momentos distintos nos sistemas logísticos dos seis Navios, a saber: pedidos de sobressalentes de símbolo de jurisdição “ $\mathrm{CH}$ ” pendentes durante 24 períodos mensais (tempo 
limite normatizado para pendência de pedidos de sobressalentes) e a reconsideração dos pedidos pendentes em face do compartilhamento de informações de estoque em excesso nos varejistas (Navios).

A quantidade de pedidos pendentes por número de estoque foi extraída da Base de Dados do SISBORDO, ao passo que a quantidade em excesso nos Navios constitui-se do resultado da subtração entre a quantidade existente a bordo por número de estoque e a quantidade prevista na Lista de Dotação de Bordo de cada Navio. Tais dados encontram-se armazenadas no SISBORDO.

Constata-se a existência de 405 itens, os quais são considerados como Stock Keeping Unit (SKU) previstos em pedidos pendentes (em dívida) para os seis Navios, porém em excesso em outros Navios distintos do Navio solicitante. A quantidade desses itens de sobressalente corresponde a 6,61\% de toda dotação de bordo de itens SJ "CH" (6.124 itens SKU). Ademais, aproximadamente 99\% dos 405 itens possuem aquisição em fontes de obtenção internacionais.

O não compartilhamento da informação entre distintos escalões envolvidos no processo de abastecimento de sobressalentes traz reflexos negativos para o desempenho logístico do sistema. Uma importante medida de desempenho logística é o nível de serviço. $\mathrm{O}$ cálculo do nível de serviço sem a utilização do SISBORDO considera os pedidos atendidos pelo SAbM ante às solicitações emitidas por cada Navio durante 24 meses. É efetuada uma reanálise dos pedidos pendentes, realizando cotejo entre os itens de sobressalentes solicitados por meio destas e os itens de sobressalentes em excesso em outros Navios. Nesta reanálise, os pedidos pendentes são considerados atendidos utilizando o estoque em excesso de outro Navio.

Por meio da Tabela 2, é apresentada a quantificação de incremento em termos de nível de serviço, por FCN, a partir do compartilhamento de informações supracitadas. Para todas as FCN, é percebido um incremento relativo de 21,9\% no nível de serviço com a utilização do SISBORDO se comparado com o nível de serviço sem a utilização do SISBORDO.

TABELA 2 - Nível de Serviço por Navio sem a utilização do SISBORDO e com a utilização do SISBORDO.

\begin{tabular}{clcc}
\hline Navio & Nomenclatura & $\begin{array}{c}\text { Nível de Serviço } \\
\text { sem utilização do } \\
\text { SISBORDO para } \\
\text { itens SJ “CH” (\%) }\end{array}$ & $\begin{array}{c}\text { Nível de Serviço com } \\
\text { utilização do } \\
\text { SISBORDO para itens } \\
\text { SJ “CH” (\%) }\end{array}$ \\
\hline F40 & Fragata Niterói & 36,87 & 38,30 \\
F41 & Fragata Defensora & 34,86 & 56,88 \\
F42 & Fragata Constituição & 37,60 & 47,39 \\
F43 & Fragata Liberal & 39,32 & 44,72 \\
F44 & Fragata Independência & 39,94 & 45,60 \\
F45 & Fragata União & 37,91 & 43,21 \\
\hline Média & \multicolumn{3}{c}{37,75} \\
\hline \multicolumn{2}{c}{ Fonte: Os autores }
\end{tabular}

Embora houvesse a utilização apenas de sobressalentes da família SJ “CH”, constatase uma boa aproximação nos níveis de serviço calculados, uma vez que ao considerar todas as famílias de sobressalentes, a média do nível de serviço para as FCN é de 30,35\% no período considerado sem a utilização do SISBORDO.

Há de se observar que os benefícios do compartilhamento da informação não se restringem à elevação dos níveis de serviço, trazendo, ainda, redução do custo logístico e dos tempos de atendimento, impactando positivamente os vetores de serviço logístico: disponibilidade, desempenho operacional e confiabilidade [5]. Tais reflexos não foram quantificados por não fazerem parte do escopo do presente trabalho. Entretanto, segue uma ilustração sobre os mesmos, os quais poderão ser abordados em futuras linhas de pesquisa sobre o tema. 
A título de exemplo, entre os 405 números de estoque citados acima, identifica-se o item "rolamento de esferas anelar", individualizado pelo NE 3110-BR-287-7378, para o qual há 03 unidades em excesso, distribuídas pelos Navios F40 e F45, ao mesmo tempo em que há 03 unidades em dívida, para atendimento do Navio F44. Tal item tem um custo unitário de R\$ 13.691,37 e é adquirido no exterior, com um tempo de procura e aquisição de aproximadamente 10 meses. Ressalta-se o custo de distribuição física será majorado em razão do custo de importação e tráfego de carga da Inglaterra para o Brasil.

Na hipótese do compartilhamento da informação, as quantidades em excesso seriam fornecidas aos meios demandantes, implicando atendimento praticamente imediato da necessidade dos meios demandantes, redução do custo de imobilização de capital decorrente da permanência do item em excesso em outros meios, e economia decorrente da não necessidade de realização de desembolso para aquisição do item no exterior e seu transporte para o país.

Resta consignar que a utilização dos estoques em excesso para atender aos pedidos antes pendentes reduzirá também o efeito chicote ao longo de toda a Cadeia de Suprimento de Sobressalentes, uma vez que os níveis de estoques por SKU em excesso nos CD sofrerão diminuição imediata de $69,88 \%$. Isso favorece a possibilidade de futuras reposições dos itens de sobressalente mantidos em excesso nos Navios, após a demanda por outra Fragata. Ressalta-se, também, que a utilização dos estoques em excesso gera uma redução de aproximadamente dois milhões de reais com custo de manutenção.

Os resultados desta análise são apresentados nos quadros a seguir, nos quais são apresentadas, em primeira instância, as quantidades de itens que deveriam ser mantidos em estoques nos CD para atender aos pedidos em dívida (Quadro 1), e, logo em seguida, o custo de estoque em excesso mantido nos Navios (Quadro 2).

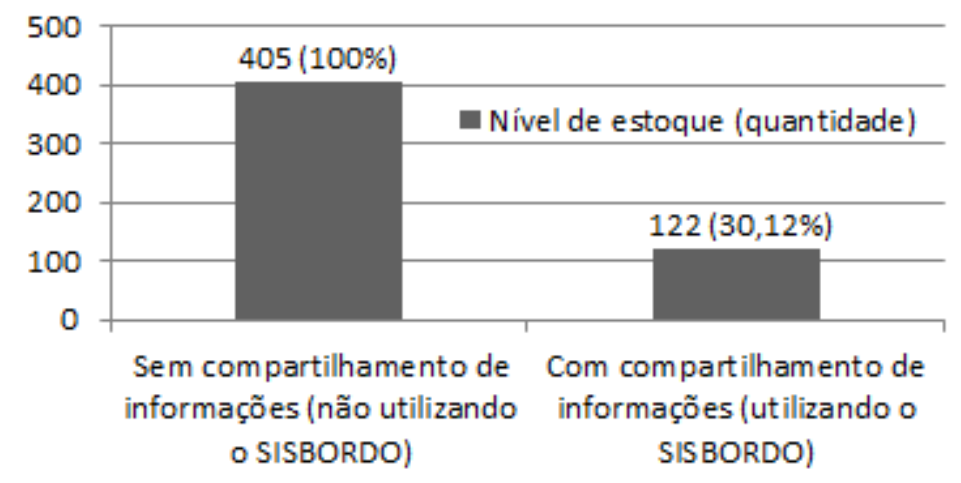

QUADRO 1 - Quantidade de itens que deveriam ser mantidos em estoques nos CD para atender aos pedidos em dívida.

Fonte: Os autores

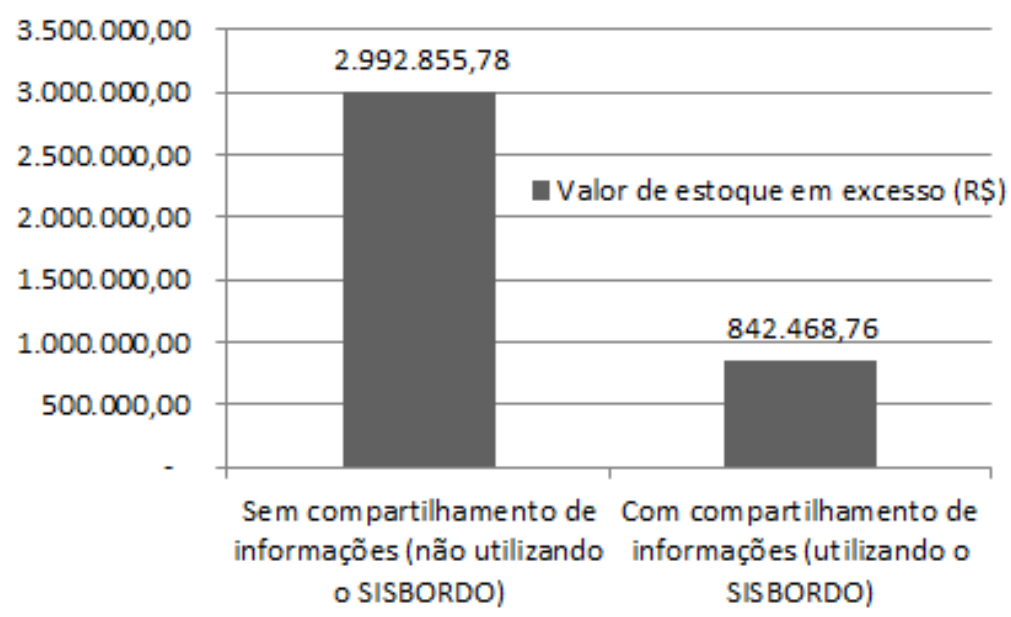

QUADRO 2 - Custo de Estoque em excesso mantido nos Navios (em R\$)

Fonte: Os autores 
Por conseguinte, algumas causas do efeito chicote serão impactadas pelo aperfeiçoamento do compartilhamento de informações, como o prazo de entrega, previsão de demanda, receio de quebra de estoque, política de reposição, política de estoque, entre outros. Ao considerar as informações do SISBORDO, o Centro de Controle de Inventários da Marinha deverá efetuar ajustes quantitativos e qualitativos junto aos Fornecedores em termos de quantidade e itens por lote de encomenda, acarretando maior visibilidade da demanda por parte dos Fornecedores.

Aliar o conhecimento de estoques em excesso e o consumo de estoques nos varejistas por manutenção com a classificação por Símbolo de Jurisdição de itens de sobressalente atrelada aos departamentos de bordo, fará com que o Centro de Controle e Inventário agregue informações relevantes para a revisão de métodos de previsão de demanda. A título de exemplo, tem-se a utilização do two-step method [18] ou a utilização de modelo de classificação para prever o desempenho do método de previsão de demanda de sobressalentes, como abordado pela Marinha Sul Coreana [27], visando, dentre outras vantagens, à acurácia da previsão de demanda.

\section{CONCLUSÃO}

Foram expostos benefícios do compartilhamento de informações, por meio do SISBORDO, entre o SAbM e os Navios apoiados angariados para o desempenho da Cadeia de Suprimento de Sobressalentes da MB, ao majorar vetores de serviço logístico, dentre os quais se destaca a disponibilidade. Considera-se, também, a diminuição do efeito chicote ao longo de toda a cadeia, bem como a redução do capital imobilizado em estoques dos Centros de Distribuição e nos Navios. Além destes, outro fator positivo é a redução do custo de estoque em excesso.

Por ocasião da tomada de decisão ante ao problema logístico, dispor de informações consistentes, de forma rápida, com o formato adequado integrado em todos os níveis organizacionais, refletirá, diretamente, no aumento da competitividade da Cadeia de Suprimento de Sobressalentes da Força, agregando valor ao esforço logístico dos órgãos pertencentes ao SAbM. Para a Cadeia de Suprimentos de Sobressalentes, dispor de eficiente e eficaz controle de inventário de sobressalentes estocados nos Navios (varejistas) torna-se um desafio para que o compartilhamento de informação por meio do SISBORDO seja incrementado em confiabilidade, em acurácia de previsão de demanda pelo Órgão de Controle de Inventário e em redução do custo de distribuição física.

Portanto, os benefícios percebidos ao longo de toda a cadeia logística de sobressalentes das Fragatas Classe Niterói resultam em maior disponibilidade e eficiência logística dos Navios que participam de patrulhas navais nas bacias petrolíferas da Amazônia Azul, propiciando assim a permanência e a defesa nas áreas de exploração das riquezas do Pré-sal.

Contribuições futuras poderão estudar a viabilidade de utilização da Tecnologia de Informação, tal como o uso de Radio Frequency IDentification (RFID), nos estoques de sobressalentes dos Navios, a fim de proporcionar maior rastreabilidade, rapidez e acurácia de inventário [30].

\section{REFERÊNCIAS BIBLIOGRÁFICAS}

[1] ALI, M. M.; BOYLAN, J. E.; SYNTETOS, A. A. Forecasts errors and inventory performance under forecast information Sharing. International Journal of Forecasting. n.28, p. 830-841, 2012.

[2] BACCHETTI, A.; SACCANI, N. Spare parts classification and demand forecasting for stock control: investigating the gap between research and practice. Omega 40. p. 722737, 2012. 
[3] BALLOU, R. H. Gerenciamento da Cadeia de Suprimentos/Logística Empresarial. Porto Alegre: Editora Bookman, 2006.

[4] BANDYOPADHYAY, S.; BHATTACHARYA, R. A review of the causes of bullwhip effect in a supply chain. Int J Adv Manuf Technol. n 54, p 1245-1261, 2011.

[5] BOWERSOX, D. J.; CLOSS, D. J. Logística Empresarial: o processo de integração da cadeia de suprimento. Editora Atlas. São Paulo, 2009.

[6] BRASIL. Lei n. ${ }^{\circ}$ 8.666, de 21 de junho de 1993. Regulamenta o art. 37, inciso XXI, da Constituição Federal, institui normas para licitações e contratos da Administração Pública e dá outras providências. Presidência da República. Disponível em: <http://www.planalto.gov.br/ccivil_03/Leis/L8666cons.htm>. Acesso em: 29 jan 2014.

[7] CHEN, Y. H.; LOW, C. A model measurement system for collaborative supply chain partners. Journal of Manufacturing Systems. n 32, p 180-188, 2013.

[8] CLAUSEWITZ, Carl Von. Da Guerra. Alemanha, 1832.

[9] COUNCIL OF SUPPLY CHAIN MANAGEMENT. Terms and Glossary, 2010. Disponível em< http://cscmp.org/sites/default/files/user_uploads/resources/downloads/ glossary.pdf $>$. Acesso em: 29 jan 2014.

[10] DANIEL, E. H. R; FOLINAS, D. K. Estimating the impact of ERP Systems on Logistics System. International Journal of Enterprise Information System. n 8, p 114, 2012.

[11] DINTER, B. Success factors for information logistics strategy - An empirical investigation. Decision Support Systems, 2012.

[12] DISNEY, S. M., HOSODA, T. A delayed supply chain: incentives for upstream players. Omega 40. P 478- 487, 2012.

[13] ESTADO-MAIOR DA ARMADA. EMA-400: Manual de Logística da Marinha, Brasília, DF, 2003.

[14] FAN, C. Y.; FAN, P. S; CHANG, P. C. A system dynamics modeling approach for a military weapon maintenance supply system. International Journal Products Economics. n 128, p.457-469, 2010.

[15] FORRESTER, J. W. Industrial dynamics - a major breakthrough for decision mabers. Harvard Business Review. n 4, p37-66, 1958.

[16] GIL, A. C. Como elaborar projetos de pesquisa. São Paulo, v. 5, 2002.

[17] GUNASEKARAN, A.; NGAI, E. W. T. Decision support systems for logistics and supply chain management. Decision Support Systems, n. 52, p. 777-778, 2012.

[18] JAARSVELD, W. V., ROMEIJNDERS, W., TEUNTER, R. A two-step method for forecasting spare parts demand using information on component repairs. European Journal of Operational Research. n 220, p 386-393, 2012. 
[19] JANVIER-JAMES, A. M., A new introduction to supply chains and supply chain management: definitions and theories perspective. International Business Research. Vol 5 n 1. p 194-207. 2012

[20] JOMINI, Antoine Henri. A Arte da Guerra. França, 1836.

[21] KOVACEVIC, I. et al. Application of transactional analysis in bullwhip effect analysis. Anfiteatru Economic. n 33, p 210-223, 2013.

[22] LAKATOS, E. M.; MARCONI, M. A. Fundamentos da Metodologia Científica. 3 ed. rev. e ampl. São Paulo: Atlas, 1991.

[23] LAMBERT, D. M.; COOPER, M. C.; PAGH, J. D. Supply chain management: implementation issues and research opportunities. The International Journal of Logistics Management. n. 8, p. 1-19, 1998.

[24] LI, C. Controlling the bullwhip effect in a supply chain system with constrained information flows. Applied Mathematical Modeling. n 37, p 1897-1909, 2013.

[25] LI, C. e LIU, S. A robust optimization approach to reduce the bullwhip effect of supply chains with vendor order placement lead time delays in an uncertain environment. Applied Mathematical Modeling. n 37, p 707-718, 2013.

[26] MELLAT-PARAST, M., Supply Chain quality management: an inter-organizational learning perspective. Supply Chain Quality Management. P 511-529, 2012.

[27] MOON, S.; HICKS, C.; SIMPSON, A. The development of a classification model for predicting the performance of forecasting methods for naval spare parts demand. Int. J. Production Economics. n 143, p 449-454, 2013.

[28] MOON, S.; HICKS, C.; SIMPSON, A. The development of a hierarchical forecasting method for predicting spare parts demand in the South Korean Navy - A case study. Int. J. Production Economics. n 140, p 794-802, 2012.

[29] NASLUND, D.; HULTHEN, H. Supply chain management integration: a critical analysis. Benchmarking: an International Journal. Vol 19, n 5/4, p 481- 501, 2012.

[30] RUSSEL, S. H., Supply Chain Management: More Than Integrated Logistics. Air Force Journal of Logistics. n 3, p 88-97, 2011.

[31] SECRETARIA-GERAL DA MARINHA. SGM-201: Normas para o Abastecimento na Marinha, $6^{\mathrm{a}}$ rev., Brasília, DF, 2009.

[32] THORPE. Logística Pura: a ciência da preparação para a guerra. Newport, RI, 1917.

[33] TURBAN, E.; McLEAN, E.; WETHERBE, J. Tecnologia da Informação para Gestão. Porto Alegre. Editora Boowman, 2004.

[34] WANKE, P. Gestão de Estoques na Cadeia de Suprimento: Decisões e Modelos Quantitativos. Editora Atlas, São Paulo, 2011. 